\title{
Erratum
}

\section{SOME NOTES ON MEDICAL ENGLISH}

Vincenzo Lanza

In the above-mentioned paper, an unfortunate typesetting error occurred that placed some text out of order. In paragraph 1 , line 8 , the phrase "as well as. .." continues in paragraph 5, line 12: "informed consent. .." In paragraph 9, line 10, the phrase "as well as..." continues in paragraph 1, line 8, "reproductive..." In paragraph 5, line 11, the phrase “...highly specialized" continues in paragraph 9, line 10: "topic..." 